\title{
O currículo e as relações de gênero na primeira infância
} The curriculum and gender relations in early childhood

\author{
Dayse Costa dos Santos ${ }^{1 *}$, Delza Cristina Pinheiro ' , Enimeyre de Melo Cavalcanti ${ }^{1}$, \\ Elisangela Santos de Amorim ${ }^{2}$
}

\begin{abstract}
RESUMO
Esta pesquisa se propõe a discutir sobre o currículo e as relações de gênero na educação infantil. Tem como objetivo refletir como as práticas curriculares na educação infantil reproduzem os preconceitos baseados nas diferenças a partir do sexo. Para isso, nos fundamentamos nas leituras dos seguintes autores: Finco (2005), Ariès (2006), Pacheco (2005), Louro (2001) entre outras/os. Para o desenvolvimento da pesquisa, foram feitos levantamentos bibliográficos e pesquisa documental com foco nas práticas curriculares, relações de gênero na primeira infância e os seus desafios nos dias atuais. Percebemos no decorrer da pesquisa que as práticas curriculares na perspectiva de gênero na educação infantil são compartilhadas ainda hoje sobre as identidades de masculino e feminino como condutas oficiais da sociedade que acabam sendo refletidas na escola. Entendemos no decorrer da pesquisa que o currículo não pode ser posto de maneira neutra, ele requer da/o professora/o um posicionamento crítico sobre sua prática.
\end{abstract}

Palavras-chave: Currículo; Gênero; Educação infantil.

\footnotetext{
ABSTRACT

This research aims to discuss the curriculum and gender relations in early childhood education. It aims to reflect on how curricular practices in early childhood education reproduce prejudices based on gender differences. For this, we base ourselves on the readings of the following authors: Finco (2005), Ariès (2006), Pacheco (2005), Louro (2001) among others. For the development of the research, bibliographic

${ }^{1}$ Mestranda em Educação pelo Programa de Pós-Graduação em Gestão de Ensino da Educação Básica (PPGEEB) da Universidade Federal do Maranhão (UFMA). *E-mail: dayse.costa@discente.ufma.br.

2 Departamento de Educação I da Universidade Federal do Maranhão (UFMA), docente do Programa de Pós-Graduação em Gestão de Ensino da Educação Básica (PPGEEB) da Universidade Federal do Maranhão (UFMA).
} 
surveys and documentary research were carried out with a focus on curricular practices, gender relations in early childhood and their current challenges. We realized during the research that the curricular practices from a gender perspective in early childhood education are still shared today about male and female identities as official behaviors of society that end up being reflected in school. In the course of the research, we understand that the curriculum cannot be set in a neutral way, it requires from the teacher a critical position on their practice.

Keywords: Resume; Gender ; Child education.

\section{INTRODUÇÃO}

Refletir sobre o currículo e as relações de gênero no âmbito da educação infantil permite questionamentos sobre sua trajetória histórica em relação à intervenção e o papel da cultura no processo formativo e de socialização das crianças, ressaltando suas primeiras vivências no espaço educacional.

O diálogo sobre o currículo na educação básica é complexo, sendo também a educação complexa, e são vários os desafios das professoras e dos professores em relação a sua profissão docente, é necessário que se redefinam para acompanhar as demandas da sociedade. (IMBERNÓN, 2011).

Desde os primeiros anos de vida, aprendemos de maneira cultural que existem coisas que são de menino e coisas que são de meninas, assim como cores, determinados objetos e comportamentos. A Instituição Educativa Infantil em diferentes ações, por vezes, distingue o gênero, como o estabelece por meio de gestos, maneiras de agir, símbolos e palavras produzidas nesse espaço que vão sendo aprendidas pelas crianças durante a trajetória escolar (FINCO, 2005).

Atribuem-se nesses âmbitos à menina qualidades com

o sensível, bem comportada e amorosa. Entretanto, para o menino são atribuídos sinônimos como sem disciplina, inteligente e desleixado. No ambiente familiar as diferenças entre gênero, podem ser observadas no modo das vestimentas, nas atividades domésticas, no andar e até mesmo na escolha de um brinquedo (SOUZA, 2000; SANTOS, 2004).

Há uma relação básica entre gênero de determinado sujeito e suas qualidades ou características biológicas que acabam por definir como sexo feminino ou masculino, essas relações ocorrem principalmente nos anos inicias da criança e durante a adolescência (BRASIL, 1998). 
Nesse sentido, o presente trabalho tem o objetivo de refletir sobre às práticas curriculares na educação infantil levando em consideração as relações de gênero. Antes dessa reflexão, entende-se a necessidade de um breve histórico sobre a descoberta da primeira infância, visto que nem sempre a criança foi tida como um sujeito em sua primeira fase de vida, com características e particularidades que merecem atenção e respeito, abordaremos também no decorrer deste artigo, a importância da superação de preconceitos de Gênero relativos as práticas curriculares transgressoras na educação infantil e o reconhecimentos das diferenças como forma de superação dos preconceitos de gênero na primeira infância.

Diante desse quadro, levantamos a seguinte problemática da nossa investigação: Como ocorrem as práticas curriculares da educação infantil na perspectiva do Gênero?

Este artigo se insere no do tipo de pesquisa bibliográfica, de cunho qualitativa e da pesquisa documental. Entende-se por pesquisa qualitativa, segundo Richardson (1999, p.79) “Além de ser uma opção do investigador, justifica-se, sobretudo, por ser uma forma adequada para entender a natureza de um fenômeno social”.

Esperamos com esta pesquisa refletir sobre as práticas curriculares e as relações de gênero na primeira infância, contribuindo no campo educacional sobre a temática estudada e que promova reflexões a respeito da superação de preconceitos de Gênero na Educação Infantil

\section{REFLEXÕES SOBRE CONCEPÇÃO DE INFÂNCIA, GÊNERO e CURRÍCULO}

A história da criança na idade média foi marcada por uma sociedade absorta, alheia as peculiaridades e cuidados necessários em tenra idade Desse modo, ser criança neste período era um grande desafio, sendo comparadas e tratadas como adultos, que possuíam deveres e obrigações impróprias a sua idade, frequentavam ambientes perigosos e eram expostas a situações insalubres que muitas vezes levavam-nas a serem acometidas por doenças, não tinham-se preocupação com os aspectos físicos, cognitivos ou emocionais.

De acordo com Ariès (2006),

Até por volta do século XII, a arte medieval desconhecia a infância ou não tentava representá-la. É difícil crer que essa ausência se devesse a incompetência ou a falta de habilidade. É mais provável que não houvesse lugar para a infância nesse mundo. (ARIÉS 2006, p.17). 
Em termos históricos, com a crescente demanda e a inserção de mulheres da classe média no mercado de trabalho novos espaços foram criados, as Instituições de Educação Infantil que estas nasceram primordialmente com a finalidade de atender a necessidade de uma época em que a revolução industrial trouxe oportunidades de empregos. Uma parcela das mulheres conseguiram se inserir no mercado de trabalho, com isso houve uma crescente necessidade de abertura de creches para que as crianças pudessem permanecer enquanto suas mães trabalhavam (KUHLMANN JR, 1998).

Sendo assim, o cuidado e o assistencialismo foram as principais características desses espaços que eram localizados próximos às fabricas, onde ofereciam comida e abrigo, criados principalmente para os filhos dos operários. A primeira creche brasileira foi inaugurada ao lado de uma Fábrica no ano de 1988 no Rio de Janeiro, o espaço servia como assistência para as mães deixarem seus filhos enquanto trabalhavam. (KUHLMANN JR, 1998).

Historicamente, a valorização da educação infantil no percurso do currículo nem sempre foi valorizada em suas especificidades e vistas como necessárias as práticas pedagógicas (ARIÈS, 1973). Portanto, diante do cenário que aqui se faz sobre a infância onde a criança é a principal protagonista, deve se ressaltar a importância da educação e o atendimento a elas desde bem pequenas, no seio familiar, a entrada na creche e pré-escola. Reflete-se também, que a cada dia as instituições educativas voltadas para o público infantil deve se aprimorar através de práticas lúdicas e significativas que coloquem a criança como protagonista no seu processo de desenvolvimento integral, reconhecendose como parte integrante do todo e como de fato um sujeito de direitos.

Nessa perspectiva e em consonância com Gouvêa et al. (2016, p.16), entende-se que:

a criança não é apenas uma etapa cronológica na evolução da espécie humana a ser estudada pela biologia ou pela psicologia do desenvolvimento, mas sim um ser que participa da criação da cultura através do uso criativo da linguagem na interação com seus pares, adultos e crianças, mas também com as coisas ou os objetos que existem ao seu redor.

Dessa forma, enfatiza-se o conceito de criança adotada nesse estudo como, um sujeito social e histórico que está inserido em uma sociedade na qual partilha de uma determinada cultura. É profundamente marcada pelo meio social em que se desenvolve, mas também contribui com ele (BRASIL, 2006). 
Nesta perspectiva, a criança é "um ser de direitos", conforme afirma as Diretrizes Curriculares Nacionais para Educação Infantil (DCNEI) (2010),

a criança é um sujeito histórico e de direitos que, nas interações, relações e práticas cotidianas que vivencia, constrói sua identidade pessoal e coletiva, brinca, imagina, fantasia, deseja, aprende, observa, experimenta, narra, questiona e constrói sentidos sobre a natureza e a sociedade, produzindo cultura. (BRASIL, 2010, p.12)

Desta forma, podemos afirmar que é errôneo o pensamento de que haja um tipo de infância única e universal, quando na verdade o conceito é plural, pois a exemplo, a cada geração as crianças mudam as brincadeiras, as músicas populares, o modo de vestir, agir, pensar e falar estão sempre em constante evolução. Cada cultura possui sua particularidade e colabora de maneira efetiva na construção de valores do indivíduo.

Tenreiro (2015) constata-se que na verdade,

a infância é uma etapa importante da vida da criança, pois é nessa fase que são definidos os valores que a criança levará para o resto da vida e a formação do seu caráter. Por ser uma fase de construção de conhecimentos, tudo que está ao seu redor pode influenciar em determinados comportamentos e decisões que poderão ser refletidas no futuro. (TENREIRO 2015, p. 106).

Atualmente a Educação infantil é reconhecida como a primeira etapa da educação básica e possui como objetivo o desenvolvimento integral da criança por meio de interações e brincadeiras em diferentes campos de experiências onde poderão usufruir dos direitos de aprendizagens: conviver, brincar, participar, explorar, expressar e conhecer-se e essa modalidade da educação é reconhecida pela Base Nacional Comum Curricular (BNCC) como,

Nas últimas décadas, vem se consolidando, na Educação Infantil, a concepção que vincula educar e cuidar, entendendo o cuidado como algo indissociável do processo educativo. Nesse contexto, as creches e pré-escolas, ao acolher as vivências e os conhecimentos construídos pelas crianças no ambiente da família e no contexto de sua comunidade, e articulá-los em suas propostas pedagógicas, têm o objetivo de ampliar o universo de experiências, conhecimentos e habilidades dessas crianças, diversificando e consolidando novas aprendizagens, atuando de maneira complementar à educação familiar - especialmente quando se trata da educação dos bebês e das crianças bem pequenas, que envolve aprendizagens muito próximas aos dois contextos (familiar e escolar), como a socialização, a autonomia e a comunicação. (BRASIL, 2018, p37).

Como se observa a Educação das crianças na primeira infância ocorre por meio da dicotomia educar e cuidar, e uma ação não é menos importante que a outra. 
Portanto, devem-se articular práticas curriculares que valorize as particularidades independente do gênero.

Segundo Carvalhar (2009, p.34) o termo gênero foi, oriundo da gramática, pelas feministas americanas, para regularizar a diferença sexual. Anterior a isso, o termo era restrito à gramática para determinar o "sexo" dos substantivos. Com isso elas ampliaram o conceito de gênero para remeter-se aos aspectos socialmente construídos na identificação sexual ressaltando as conotações sociais de gênero em divergência com as características físicas de sexo.

Gênero é compreendido como "as características sexuais são compreendidas e representadas ou, então, como são 'trazidas para a prática social e tornadas parte do processo histórico.” (LOURO, 2001, p.22). Para Scott (1995) as distinções compreendidas entre os sexos são compostas em relações sociais e de poder, e esta visão é diferenciada da que considera o sexo por fatores biológicos.

Louro (2001) complementa ao afirmar que essa diferença é concebida nas relações de poder, em outras palavras, esse processo de distinção entre feminino ou masculino existe uma hierarquia, onde alguns são colocados em posição maior.

Para a sociedade em geral e corroborando com Buther (1999) os "corpos" que escapam das regras de masculino ou feminino, vistos pela sociedade, são considerados errados, fora do normal, estranhos e são inseridos à margem das preocupações curriculares, pois não fazem o que é considerado ou aceitam pelo seu sexo. A educação atual e suas práticas curriculares são direcionadas de acordo com a prescrição de cada sexo.

Pacheco (2005) afirma que o conceito de currículo ao longo dos anos tem passado por modificações, antes era visto somente como plano de curso ou sentido de cursos, atualmente tem sido considerado como suporte de formação dos sujeitos ou formação humana. Nesse sentido, para o autor o currículo é uma dança e seus movimentos vão dando sentido ao espaço educacional.

Dessa forma,

O currículo nunca é apenas um conjunto neutro de conhecimentos, que de algum modo aparece nos textos e nas salas de aula de uma nação. Ele é sempre parte de uma tradição seletiva, resultado da seleção de alguém, da visão de algum grupo acerca do que seja conhecimento legítimo. É produto das tensões, conflitos e concessões culturais, políticas e econômicas que organizam e desorganizam um povo. (APPLE, 2006, p. 59). 
Compreendemos então que o currículo não é um campo neutro pois é concebido através das relações de poder, os vários conceitos do termo currículo não exprimem realidades distintas apenas demonstram a interpretação teórica em cada contexto, "as ênfases são variadas: o conteúdo, a experiência, as atividades ou a própria organização curricular, mas a realidade descrita não se modifica. É, então, uma questão de perspectiva e não propriamente de polissemia.” (PEDRA, 1997, p.31).

\section{O QUE FALAM OS DOCUMENTOS QUE NORTEIAM A EDUCAÇÃO BÁSICA SOBRE GÊNERO NA EDUCAÇÃO INFANTIL}

Nesta seção vamos refletir sobre o currículo em suas funções de ensinar e aprender na perspectiva do gênero na educação infantil e os documentos que norteiam a educação básica dentro desse contexto. Enfatizaremos o termo gênero neste artigo como "um mecanismo através do qual se produzem e se naturalizam as noções de masculino e de feminino" (BUTLER, 2006, p. 70).

Silva (2010) nos faz refletir que as práticas pedagógicas ou educativas não podem ser neutras, porque o currículo que está em torno dela é um instrumento político, de conhecimentos e culturas, as instituições escolares em suas práticas curriculares constroem e participam diretamente das identidades de meninos e meninas. Nesse sentido, "O currículo é lugar, espaço, território. O currículo é relação de poder. O currículo é trajetória, viagem, percurso" (SILVA, 2015, p.150).

Nessa perspectiva, na intenção de refletirmos melhor sobre as práticas curriculares em torno da temática de gênero na educação infantil buscamos analisar o que tratam as legislações acerca do assunto, enfatizaremos de forma breve sobre a Constituição Federal (CF/1988), a Lei de Diretrizes e Bases da Educação (LDB/Lei n ${ }^{\circ}$ 9.394/1996), as Diretrizes Curriculares Nacionais para a Educação Infantil (DCNEI/Resolução n 5/2009) e a Base Nacional Comum Curricular (BNCC/Resolução $\left.n^{\circ} 2 / 2017\right)$.

Nos documentos normativos da educação básica as abordagens sobre a temática gênero não são citadas explicitamente, observamos que a ausência do uso da palavra "gênero" acaba por promover entendimentos limitados ou restrito por sujeitos que não levam a sério a importância da temática para formação de identidades de nossas crianças. 
Ao analisarmos a Constituição Federal de 1988, não foi identificado nenhum conceito de referência à palavra gênero de forma explicita e clara, no entanto, é necessário avaliarmos o contex to histórico da época, o diálogo sobre a questão ainda era receoso e tímido, no entanto de forma Geral a Constituição traz de forma ampla o conceito de igualdade de sexo ou entre homens e mulheres, conforme observamos em seu artigo $3^{\circ}$ :

I - construir uma sociedade livre, justa e solidária; [...] III - erradicar a pobreza e a marginalização e reduzir as desigualdades sociais e regionais; IV - promover o bem de todos, sem preconceitos de origem, raça, sexo, cor, idade e quaisquer outras formas de discriminação (BRASIL, 1988, p. 01).

A Lei de Diretrizes e Bases da Educação Nacional - LDB (Lei de $n^{\circ}$ 9.394/1996) que foi aprovada anos depois da Constituição de Federal de 1988 assim como a Constituição Federal de 88 não se menciona o termo "gênero" de forma objetiva, porém, a referida Lei de ${ }^{\circ}$ 9.394/1996 assim como a Constituição Federal de 1988 traz conceitos sobre a formação de indivíduos e que o ensino e educação são exigidos através da igualdade de acesso (BRASIL, 1996).

As Diretrizes Curriculares Nacionais para a Educação Infantil de forma geral aborda sobre a temática "gênero", enfatizam sobre a construção de novas perspectivas de sociabilidade e subjetividade comprometidas com a democracia e com o combate as diferentes formas de opressão sejam elas etárias, socioeconômicas, étnico-racial, de gênero, regional, linguística e religiosa. Sendo o seguinte:

[...] novas formas de sociabilidade e de subjetividade comprometidas com a ludicidade, a democracia, a sustentabilidade do planeta e com o rompimento de relações de dominação etária, socioeconômica, étnico/racial, de gênero, regional, linguística e religiosa. (BRASIL, 2010, p. 17).

Segundo Carvalhar (2009, p.34) o termo gênero foi, oriundo da gramática, pelas feministas americanas, para regularizar a diferença sexual. Anterior a isso, o termo era restrito à gramática para determinar o "sexo" dos substantivos. Com isso elas ampliaram o conceito de gênero para remeter-se aos aspectos socialmente construídos na identificação sexual ressaltando as conotações sociais de gênero em divergência com as características físicas de sexo.

Gênero é compreendido como "as características sexuais são compreendidas e representadas ou, então, como são 'trazidas para a prática social e tornadas parte do processo histórico." (LOURO, 2001, p.22). Para Scott (1995) as distinções 
compreendidas entre os sexos são compostas em relações sociais e de poder, e esta visão é diferenciada da que considera o sexo por fatores biológicos.

Louro (2001) complementa ao afirmar que essa diferença é concebida nas relações de poder, em outras palavras, esse processo de distinção entre feminino ou masculino existe uma hierarquia, onde alguns são colocados em posição maior.

Com o Parâmetro Curriculares Nacionais, a temática sobre sexualidade tornou-se obrigatória como tema transversal, neste sentido, ela não é mais especifica somente das matérias de Biologia, e sim deve ser ministrada em todas os componentes curriculares (BRASIL, 1997). Essa mudança trouxe benefícios por poder dialogar diretamente com as dúvidas surgidas em meio a sexualidade.

Nesta perspectiva:

As manifestações de sexualidade afloram em todas as faixas etárias. Ignorar, ocultar ou reprimir são as respostas mais habituais dadas 6 pelos profissionais da escola. Essas práticas se fundamentam na ideia de que o tema deva ser tratado exclusivamente pela família (BRASIL, 1997, p. 111).

Em reflexão, o currículo da Educação Infantil hoje se baseia na BNCC como documento norteador das práticas educativas para as crianças bem pequenas $(0$ a 3 anos e 11 meses) e pequenas ( 4 anos a 5 anos e 11 meses) e não trata as relações de gênero, mas como aborda Menezes (2017, p. 290) :

Pelas orientações da BNCC os corpos das(os) meninas(os) na Educação Infantil são entendidos como "campos de experiências", que "constituem um arranjo curricular que acolhe as situações e as experiências concretas da vida cotidiana das crianças e seus saberes, entrelaçando-os aos conhecimentos que fazem parte de patrimônio cultural" (BRASIL, 2017, p. 36). Como é possível perceber, o discurso enunciado na BNCC estabelece que as rotinas pedagógicas nas creches e pré-escolas favoreçam a vivência de experiências corpóreas pelas crianças partindo de situações que traduzam suas culturas de pertença, como também dos grupos sociais nos quais as instituições estão inseridas. O que nos inquieta nessa trama é pensar a possibilidade de constituição da corporeidade quando as experiências com o corpo serão vividas pelas crianças apartadas das questões de gênero. Portanto, um corpo genérico, vago e esvaziado de sentidos.

Como visto na ausência da discussão sobre as relações e gênero, a BNCC aborda sobre o corpo das crianças, e não reflete sobre essa temática tão importante no desenvolvimento de nossas crianças e consequentemente do indivíduo como todo, visto que olhar a vida e pensar sobre ela, colocando-se como protagonista da própria história, remete ao reconhecimento como pessoas singulares e com peculiaridades e que as 
relações de gênero podem se traduzir como meios de criação de alteridades nas vivências das crianças em suas diferentes formas de interação.

\section{PRÁTICAS CURRICULARES E SEUS DESAFIOS PARA SUPERAÇÃO DE PRECONCEITOS DE GÊNERO NA PRIMEIRA INFÂNCIA}

Efetivar práticas pedagógicas que transgridam estereótipos de gênero na educação infantil é uma forma, se não a mais significativa, de lutarmos pela desconstrução das relações hierarquizadas a partir dos sexos no ambiente escolar. Entretanto, ainda convivemos com a resistência da escola e sociedade para que a temática não faça parte do currículo escolar. Tais comportamentos são marcados pela construção do contexto histórico e social, o que explica as reproduções das estruturas de poder que um gênero tem em relação ao outro.

Assim, para Sacristán (2000) as práticas curriculares que materializam o currículo no fazer pedagógico devem considerar substancialmente as necessidades na comunidade escolar. Desse modo, as ações desenvolvidas pelos professores partem das concepções que a escola preconiza como cruciais para o tipo de formação que será proporcionado as/aos educandas/os. Ou seja, a forma como os professores reestruturam o currículo e ao colocá-lo em prática na sala de aula na perspectiva de potencializar o processo de ensino-aprendizagem se define como práticas curriculares.

Embora existam políticas que assegurem o trabalho com ações voltadas para a educação de gênero, na prática ainda se tem oposições à educação efetiva em termos de equidade. Esse posicionamento reflete na formação dos sujeitos e na sociedade, em geral. Na contramão dessas práticas, temos educadores que resistem e manifestam, através da ressignificação dos saberes e currículo, uma educação voltada para a conscientização e erradicação de estigmas de gênero.

Nessa perspectiva, a escola enquanto instituição que abriga grupos diversos de estudantes em gênero, sexualidade, étnico, cultural, deve ser um lugar para discutir e combater os estigmas naturalizados pela sociedade. Por isso, é de fundamental importância rever a prática pedagógica que vem se desenvolvendo, se realmente está contribuindo para a construção de uma sociedade justa e igual.

Nesse sentido; 


\begin{abstract}
A Prática Pedagógica é entendida como uma prática social complexa, acontece em diferentes espaço/tempos da escola, no cotidiano de professores e alunos nela envolvidos e, de modo especial, na sala de aula, mediada pela interação professor-aluno-conhecimento. Nela estão imbricados, simultaneamente, elementos particulares e gerais. Os aspectos particulares dizem respeito: ao docente - sua experiência, sua corporeidade, sua formação, condições de trabalho e escolhas profissionais (...) (CALDEIRA; ZAIDAN, 2010, p. 2).
\end{abstract}

Assim, o exercício da prática de ensino perpassa pela formação inicial, continuada e também é resultado de sua vivência, incluindo pessoal, escolar, acadêmica e profissional. Nesse sentido, Franco (2015) nos traz a importância da reflexão crítica da prática e consciência das intencionalidades. Alerta para a necessidade do professor ter noção da categoria de gênero e consciência das práticas que exercem em prol da igualdade de gênero, observando que a partir de suas práticas é possível modificar a realidade no sentido de minimizar ou erradicar as desigualdades de gênero.

Ter pouco ou nenhum conhecimento sobre a temática pode trazer a insegurança em trabalhar as problemáticas das desigualdades de gênero, o que consequentemente limita o assunto no ambiente escolar e contribui para que a formação da identidade de gênero da criança aconteça de forma desfavorável ou diferente do que está proposto nos documentos norteadores.

Por isso, conhecer estratégias como o trabalho com o uso da linguagem pode desempenhar um forte papel na construção da identidade de gênero, uma vez que a linguagem se caracteriza como um meio de produção e reprodução das desigualdades de gênero. Nesse sentido, Louro (1999) coloca que:

[...]as diferenças estão, constantemente, sendo produzidas no meio social, através de processos linguísticos e discursivos, num campo que é político, uma vez que nele estão implicados relações de poder.

É comum ouvirmos professoras e professores se referirem à turma generalizando o tratamento masculino quando se refere a ambos os sexos. Assim como, o uso do diminuitivo para se referir às meninas e aumentativo quando se remete a meninos. Dessa forma, a linguagem é utilizada como delimitadora dos lugares do feminino e do masculino e fator de desigualdade entre os sexos. Nesse sentido, (LOURO, 1997) nos mostra que, 
[...] a linguagem continua sendo um dos principais "campos de construção de identidades, ela não apenas expressa relações, poderes, lugares, ela os institui, ela não apenas veicula, mas produz e pretende fixar diferenças" (LOURO, 1997, p. 65).

Assim, a linguagem verbal pode proporcionar no cotidiano escolar uma discriminação sexista. Para Nascimento (2014) “a educação sexista é aquela que não apenas distingue homens e mulheres, mas que transformam essas diferenças em desigualdades, que são justificadas como algo estabelecido biologicamente". Dessa forma, podemos perceber que historicamente, desde cedo vai sendo construída a ideologia do poder do patriarcalismo, "na qual são construídas as desigualdades entre homens e mulheres" (NASCIMENTO, 2014, p. 261).

É importante a/o professora/o utilizar a linguagem, os materiais didáticos e planejar suas atividades de forma reflexiva e criticamente, no sentido de possibilitar a desconstrução de conceitos e práticas discriminatórias. Assim, para Scott (1995), "as discussões sobre gênero são fundamentais no sentido de desconstruir e problematizar o pensamento binário sobre o masculino e o feminino e a lógica da dominação e submissão, passando a compreender gênero no sentido relacional".

Destarte, cabe à escola, enquanto espaço formal de formação dos indivíduos, trabalhar no sentido de promover práticas curriculares transgressoras para superar preconceitos de gênero. Para isso, se faz necessário repensar o currículo, redirecionar as formações continuadas, dialogar com a família e com a sociedade.

\section{DESAFIOS DE PROFESSORES (AS) PARA A SUPERAÇÃO DE PRECONCEITOS DE GÊNERO NA PRIMEIRA INFÂNCIA}

Para discutir as relações de gênero na educação, faz-se necessário refletir sobre as práticas educacionais no cotidiano das instituições. As relações de gênero configuram-se como um dos eixos centrais para elaboração de currículo nas escolas de educação Infantil, que atendem crianças de 0 a 5 anos de idade.

Relacionar gênero com a infância permite-nos perceber as múltiplas formas de ser menina e menino, criando oportunidades de serem elas mesmas, oportunizando vivenciar sua infância, percorrendo caminhos diferentes do âmbito familiar, primeiro grupo do qual se relacionam. 
De acordo com Menezes (2017, p. 287) "na modernidade, a construção da infância desenvolveu-se em torno de processos de disciplinamentos e dos mecanismos de controle". Antes mesmo de nascerem as crianças são expostas a regulações conforme seu sexo, as cores é o exemplo muito comum. Quando nascem, a família e a sociedade ensinam-lhe diferentes modos de pensar, é quando crianças passam a agir de acordo com os ensinamentos que reforçam desigualdades existentes entre homens e mulheres. Entretanto:

as diferenças de gênero são construídas social e historicamente na infância e na vida adulta, entendendo esses dois momentos na condição da experiência e não especificamente na idade dos sujeitos como referencia para marcar gerações e/ou períodos da vida humana. (MENEZES 2017, p. 287)

A diferenciação de gênero é um assunto que se discute atualmente e tem sido objeto de estudo de muitas pesquisas e trabalhos acadêmicos. Nesse sentido, a necessidade de se refletir sobre o lugar da temática nas políticas públicas educacionais brasileiras passa pela questão da valorização da formação das/os professoras/es e a implementação dessas políticas.

Dentro dessa perspectiva elevar a qualidade da educação no Brasil passa necessariamente em refletir sobre o pensar e o agir dos professores em se tratando das discussões sobre gênero. Envolve olhares sobre valores, formação religiosa, realidade em que se encontra a instituição, para que a formação continuada possa fornecer subsídios aos profissionais conduzirem as ações pedagógicas junto aos pequenos da educação infantil.

O debate sobre a temática gênero tem um lugar de destaque no âmbito educacional, já que entendemos a escola como um espaço democrático que visa a formação integral do cidadão.

É nessa perspectiva que Vianna e Finco (2009, p 271) diz que:

as relações das crianças da educação infantil apresentam-se como uma das formas de introdução de meninos e meninas na vida social, principalmente porque oferecem a oportunidade de estar em contato com crianças oriundas de diversas classes sociais, religiões e etnias com valores e comportamentos também diferenciados.

É no espaço da escola que acontece o processo de socialização das crianças, visto que nesse momento elas entram em contato com outras crianças e com os adultos. Muito comum nesse contexto a normatização e o disciplinamento do corpo e das atitudes dos pequenos, portanto, Giachini; Leão (2016) afirmam que que as distinções de gênero 
ocorrem de maneira mais evidente nos jogos, nos brinquedos, nas brincadeiras, nos vestuários, nos comportamentos aceitos ou não para meninos e meninas, entre outros.

Então porque considerar a abordagem sobre gênero e educação infantil? E por que trazer para esse debate sobre o papel da/o professora/o na mediação dessas questões? Trazendo a discussão sobre a importância dos saberes dos professores na prática pedagógica. Tardiff (2020 p. 31) diz: \{...\} "um professor é, antes de tudo, alguém que sabe alguma coisa e cuja função, consiste em transmitir, esse saber a outros".

Dentro dessa perspectiva, interessante problematizar como os discursos para moldar as identidades das crianças são recorrentes entre os professores da educação infantil. Esse tipo de orientação está presente na forma como professoras/es educam as crianças pequenas quando afirmam a existência de coisas para meninas e coisas para meninos.

Esse binarismo apresenta-se de forma simbólica nos discursos construídos ao longo do tempo no que diz respeito a masculinidade e a feminilidade. Historicamente as normas sociais prescrevem posturas e comportamentos deixando perceptível um esforço para que as crianças obedeçam a um padrão de normalidade quanto ser homem e ser mulher.

Segundo Finco (2004, p. 1):

desde a infância tais atitudes são enraizadas através dos relacionamentos, na família, na escola, construindo assim valores nem sempre explícitos, mas que sutilmente determinam nossos comportamentos.

O brincar faz parte do desenvolvimento infantil configurando se como a forma que as crianças usam para representar o mundo ao seu redor. É a partir das brincadeiras que elas expandem sua imaginação, levando-a a criar fantasias e situações significativas como resposta das experiências com os adultos.

Kishimoto (1999, p.18) considera que:

o brinquedo coloca a criança na presença de reproduções: tudo que existe no cotidiano, natureza e as construções humanas. Pode-se dizer que um dos objetivos do brinquedo é dar à criança um substituto dos objetos reais, para que possa manipulá-los.

Ao trazer as questões de gênero enquanto categoria de análise e discutir como as crianças brincam, não poderíamos deixar de levar em consideração o processo de formação das (os) professoras (es) da educação infantil. Louro (1997 p. 8) afirma que “os currículos, normas, procedimentos de ensino, linguagem, materiais didáticos e 
processos de avaliação contribuem para as diferenças de gênero nas series iniciais". É na brincadeira que são reforçados os estereótipos sexistas tais como: meninas são mais dóceis, calmas, passivas e aptas a realizarem atividades domésticas, para os meninos fica reservado brincadeiras que exprimem força, valentia e geralmente são orientados a não chorarem por ser uma comportamento que indica fragilidade.

O meio cultural e social do qual as crianças estão inseridas reforçam e internalizam ideias estereotipadas de papeis desempenhados por meninas e meninos. Desse modo, Leão (2016) diz que a escola é o ponto de encontro e de embates das diferenças, podendo ser instrumento eficaz para diminuir e prevenir o processo de exclusão social.

As representações de gênero reproduzidas nas instituições educativas que atendem crianças da primeira infância, implicam na maioria das vezes em relações de desigualdades entre meninas e meninos, ocasionando relações de poder de um sexo em detrimento do outro. É papel do professor está atento a essas manifestações e saber o momento devido de fazer intervenções e que subsídios irá utilizar para mediar esse processo, pois, (GIACHINI; LEAO 2016, p. 1416) trata-se de um olhar diferenciado para as relações de gênero nas brincadeiras, e quando isso acontece, o que se tem é o reforço de modelos que incitam as desigualdades sexuais e a percepção de concepções equivocadas.

Cabe as (os) professoras (os) perceberem situações de discriminação de gênero, discursos sobre papeis desempenhados por meninas e meninos e dessa forma oferecer oportunidades para as crianças exercitarem suas subjetividades e particularidades. Através da promoção de atividades que proporcione vivencias significativas sobre as questões de gênero as (os) professoras (es) devem estar atentas e sensíveis diante das situações apresentadas pelas crianças enquanto interagem.

Desta forma, o profissional deve procurar estar se atualizando constantemente e inovando a sua forma de intervir, sem atitudes estereotipadas e livres de discursos moralizantes. Dessa forma o processo de formação dos profissionais da educação se torna algo importante para os dias de hoje, já que oportunizará tanto para estes quanto para as crianças e jovens a oportunidade de ressignificar as relações de gênero e poder, perpetuadas ao longo da história que lhe foram atribuídas. 


\section{CONSIDERAÇÕES FINAIS}

Podemos perceber que em nossa sociedade ainda temos práticas que reforçam as desigualdades entre gênero, práticas que são estimuladas desde a infância e a escola ainda permanece contribuindo através da reprodução de comportamentos e atitudes sexistas.

Não podemos negar que tivemos avanços quanto aos documentos normativos e orientadores, dentre eles as Diretrizes Curriculares Nacionais para a Educação Infantil, entretanto, ainda faltam políticas que efetivem práticas no espaço escolar, possibilitando construir uma educação baseada no princípio da igualdade, objetivando a emancipação do ser humano na sociedade.

É necessário colocar no currículo e nos documentos oficiais da Educação Básica o diálogo ou discussão em volta das questões relacionadas ao gênero na educação infantil, para que a escola e suas práticas pedagógicas não perpetue informações distorcidas, preconceitos ou mitos sobre a temática.

É de causar estranheza pensar que em pleno século XXI, ainda se faz necessário discutir e lutar por direitos básicos de respeito às diferenças, principalmente no espaço escolar. Constatamos que mais do que refletir sobre desigualdades de gênero, precisamos ressignificar as práticas educativas, de forma que possamos desconstruir e desnaturalizar ações de desigualdades.

\section{REFERÊNCIAS}

APPLE. M.W. Repensando o Curriculo; SILVA, T. T da. In: MOREIRA, Antonio Flávio; Tomaz Tadeu da (Orgs.). Currículo, Cultura e Sociedade. São Paulo: Cortez, 2005, p. 39-57.

APPLE, M. W. Ideologia e currículo. 3 ed. Porto Alegre: Artmed, 2006.

ARIÈS, P. História social da criança e da família. $2^{\mathrm{a}}$ ed., Rio de Janeiro:Guanabara: 1973.

ARIÉS, Philippe. História social da criança e da família. 2. ed. - Rio de Janeiro: LTC, 2006.

BUTLER, Judith. Corpos que pesam: sobre os limites discursivos do "sexo". In: Louro, Guacira. (Org). O corpo educado:pedagogias da sexualidade. Belo Horizonte: Autentica, 1999, p. 151-17 
BRASIL. Secretaria de Educação Fundamental. Parâmetros curriculares nacionais: introdução aos parâmetros curriculares nacionais / Secretaria de Educação Fundamental. - Brasília: MEC/SEF, 1997.

BRASIL, 1998 - Referencial Curricular Nacional para Educação Infantil/ Ministério da Educação e Desporto, Secretaria de Educação Fundamental. - Brasília MEC/SEF, 1998. Volume 1.

BRASIL. Base Nacional Comum Curricular. Educação é a Base. Brasília, MEC/CONSED/UNDIME, 2017.

BRASIL. Ministério da Educação. Secretaria de Educação Básica. Diretrizes curriculares nacionais para a educação infantil / Secretaria de Educação Básica. Brasília: MEC, SEB, 2010.

BRASIL. Ministério da Educação. Secretaria de Educação Básica. Parâmetros nacionais de qualidade para a educação infantil/Ministério da Educação. Secretaria de Educação Básica - Brasília. DF, 2006.

CALDEIRA, Ana Maria Salgueiro; ZAIDAN, Samira. Prática pedagógica. In: OLIVEIRA, D.A.; DUARTE, A.M.C.;VIEIRA, L.M.F. Dicionário: trabalho, profissão e condição docente. Belo Horizonte: UFMG/Faculdade de Educação, 2010. Disponível em: < http://www.gestrado.org/pdf/328.pdf> Acesso em: 02 set 2015.

CARVALHAR, Dannielle Lameirinhas. Relações de gênero no currículo da educação infantil: a produção das identidades de princesas, heróis e sapos. Dissertação (Mestrado em Educação)- Faculdade de Educação, Universidade Federal de Minas Gerais. Belo Horizonte, 2009.

DORNELLES, Leni Vieira. MARQUES, Mara Circe. Mas o que é infância: atravessamento de múltiplos olhares. Revistas eletrônicas. V.38. n 2, p.289-298, Porto Alegre, maio-ago.2015.

FINCO, Daniela. Educação infantil, gênero e brincadeira: das naturalidades às transgressões. In: 28 ${ }^{\mathbf{a}}$ REUNIÃO ANUAL DA ANPED, 2005, Caxambú MG. Anais... Caxambu: Anped, 2005.

FRANCO, M. Amélia Santoro. Práticas de ensinar-aprender: por entre resistências e resignações. In: Educ. Pesqui., São Paulo, v. 41, n.3, p. 601-614, jul./set.2015. Disponível em: Acesso em: 26 dez. 2015.

GIACHINI, Alessandra Cristina Bolfe. LEÃO, Andreza Marques de Castro. Relações de gênero na educação infantil: apontamentos da literatura cientifica. RIAEE. V. 11. N 3, p. 1049-1422, São Paulo, 2016.

GOUVÊA, Maria Cristina Soares de. PEREIRA, Rita Ribes. SOUZA, Solange Jobim. Ser criança na educação infantil: infância e linguagem / Ministério da Educação, Secretaria de Educação Básica. - 1.ed. - Brasília: MEC /SEB, 2016. Disponível em: 
https://revistaseletronicas.pucrs.br/ojs/index.php/faced/article/download/19601/13667//. Acesso em: 03 mai. 2021.

IMBERNÓN, F. Formação docente e profissional: formar-se para a mudança e a incerteza. São Paulo: Cortez, 2011.

KISHIMOTO, Tizuko Morchida. Jogo, brinquedo, brincadeira e a educação. 3 ed.São Paulo: Cortez, 1999.

KUHLMANN JR. M. Infância e Educação Infantil: uma abordagem histórica. Porto Alegre: Mediação, 1998.

LOPES, A. C.; MACEDO, E. Teorias de Currículo. 1 ed. São Paulo: Cortez, 2011.

LOURO, Guacira Lopes. Gênero, sexualidade e educação: uma perspectiva pós estruturalista. 4 ed. Petrópolis: Vozes, 2001.

O currículo e as diferença sexuais e de gênero. In: COSTA, Marisa Vorraber (org.). O currículo nos limiar es do contemporâneo. Rio de Janeiro: DP\&A, 1999. p. 8592.

Gênero, sexualidade e educação: uma perspectiva pós estruturalista. 16 ed. - Petrópolis, RJ: Vozes, 2014.

MENEZES, Flávia Maria de. Educação infantil e gêneros nas narrativas da BNCC. Revista Veras, São Paulo, v. 7, n. 2, p. 285-297, julho/dezembro, 2017. DOI: 10.14212/veras.vol7.n2.ano2017.art314.

NASCIMENTO, Antônia Camila de Oliveira. Divisão sexual dos brinquedos infantis: uma reprodução da ideologia patriarcal. Rev. O Social em questão, ano XVII, n. 32, p. 257-276, 2014. Disponível em:

http://osocialemquestao.ser.pucrio.br/cgi/cgilua.exe/sys/start.htm?infoid=279\&sid=34 . Acesso em: 29 mai. 2021

SILVA, T. T da. Documentos de identidade: uma introdução às teorias do currículo. $3^{\text {a }}$ ed. Belo Horizonte: Autêntica, 2010

SCOTT, Joan. Gênero: uma categoria útil de análise histórica. Educação e Realidade, Porto Alegre, vol. 20, n. 2, p.71-99, jul/dez. 1995.

TARDIFF, Maurice. Saberes docentes e formação profissional. 17 ed. - Petrópolis RJ: Vozes, 2014.

TENREIRO, Maria. A formação de professores da educação infantil: distintas abordagens. José Carlos de Melo (Org.) São Luís: EDUFMA, 2015. 222p.

Recebido em: 15/10/2021

Aprovado em: 10/11/2021

Publicado em: 12/11/2021 